\title{
Simultaneous determination of inorganic anions and cations in explosive residues by ion chromatography
}

\author{
Hong-Bo Meng ${ }^{\text {a,c }}$, Tian-Ran Wang ${ }^{\mathrm{b}}$, Bao-Yuan Guo ${ }^{\mathrm{b}}$, Yuki Hashi ${ }^{\mathrm{b}}$, \\ Can-Xiong Guo ${ }^{\text {a }}$, Jin-Ming Lin ${ }^{\mathrm{c}, *}$ \\ a Faculty of Science, Beijing University of Chemical Technology, Beijing 100029, China \\ b State Key Laboratory of Environmental Chemistry and Ecotoxicology Research Center for Eco-Environmental Sciences, \\ Chinese Academy of Sciences, P.O. Box 2871, Beijing 100085, China \\ c Department of Chemistry, Tsinghua University, Beijing 100084, China
}

Received 11 November 2007; received in revised form 22 January 2008; accepted 25 January 2008

Available online 5 February 2008

\begin{abstract}
A non-suppressed ion chromatographic method by connecting anion-exchange and cation-exchange columns directly was developed for the separation and determination of five inorganic anions (sulfate, nitrate, chloride, nitrite, and chlorate) and three cations (sodium, ammonium, and potassium) simultaneously in explosive residues. The mobile phase was composed of $3.5 \mathrm{mM}$ phthalic acid with $2 \%$ acetonitrile and water at flow rate of $0.2 \mathrm{~mL} / \mathrm{min}$. Under the optimal conditions, the eight inorganic ions were completely separated and detected simultaneously within 16 min. The limits of detection $(\mathrm{S} / \mathrm{N}=3$ ) of the anions and cations were in the range of 50-100 $\mu \mathrm{g} / \mathrm{L}$ and $150-320 \mu \mathrm{g} / \mathrm{L}$, respectively, the linear correlation coefficients were $0.9941-0.9996$, and the R.S.D. of retention time and peak area were $0.10-0.29 \%$ and $5.65-8.12 \%$, respectively. The method was applied successfully to the analysis of the explosive samples with satisfactory results.
\end{abstract}

(C) 2008 Published by Elsevier B.V.

Keywords: Non-suppressed ion chromatography; Simultaneously; Inorganic explosive residues; Phthalic acid

\section{Introduction}

Ion chromatography (IC) was an important technique for the ionic compound determination. IC has excellent repeatability and extensive appliance in water quality controlling [1-5], atmosphere monitoring [6], food security [7-9], pharmaceutical [10-12], including forensic science [13,14].

Simultaneous determination of inorganic ions was very important to meet the need of real field determination. However, in most cases, anions and cations are usually determined separately using different separation systems with different types of columns and conditions. The determination of anions and cations needs more time to balance the two different columns. Thus, data on the ionic composition of a sample can be obtained either by two parallel analyses on two different ion chromatographs, or by two consecutive analyses of the same sample

\footnotetext{
* Corresponding author. Tel.: +86 1062792343 ; fax: +86 1062792343.

E-mail address: jmlin@mail.tsinghua.cn (J.-M. Lin).
}

with one instrument but with different columns and under different eluent conditions. Sometime, the amount of samples, such as the real field samples or the bio samples, was slightness not enough to be determined under twice runs. Therefore, the IC methods for the simultaneous determination both anions and cations were developed in the recent years by connecting two columns in series via a single six-port switching valve [15-17], or assembling two switching six-port valves and two detectors on flow system with two ion-exchange columns for the determination of both anions and cations [18]. Although the method which directly connected ion-exclusion/cation-exchange columns was reported in some papers [19-21], the method of directly connecting anion exchange/cation exchange in the determination was less reported. It was difficult to choose one single proper eluent for the two columns connected sequentially.

Other methods were available to determine inorganic explosive residues, such as capillary electrophoresis [13,14,22], and traditional chemical method [23]. Capillary electrophoresis has limits of poor reproducibility and sensitivity, and traditional chemical method is easily interfered by other ions existing in the 
sample matrix and of low credibility and accuracy. Hence, ion chromatography was the suitable analytical method to determine inorganic ions.

In recent years, increasing illegal uses of inorganic explosives have been observed. These inorganic explosive are easy to be synthesized, the starting materials such as inorganic salt are readily available at low cost and with excellent performance. Hence, the inorganic explosive has extensive application in different fields including industry, agriculture, irrigation military and so on. At the same time, occurrences of many explosions including terroristic explosions were also caused by inorganic explosive.

The most widely used inorganic explosives in the world were ammonium nitrate explosive, potassium chlorate explosive and black powder. After the blast of these inorganic explosives, some major ion residues of these explosives left behind from the blast. The residue ions of ammonium nitrate were mostly $\mathrm{NO}_{3}{ }^{-}$and $\mathrm{NH}_{4}{ }^{+}$; the residue ions of potassium chlorate explosive mostly were $\mathrm{Cl}^{-}, \mathrm{ClO}_{3}{ }^{-}, \mathrm{K}^{+}, \mathrm{Na}^{+}$; the residue ions of black powder mostly were $\mathrm{K}^{+}, \mathrm{Na}^{+}, \mathrm{NO}_{3}{ }^{-}, \mathrm{SO}_{4}{ }^{2-}$. The species of ions are the most important evidence used to identify the nature and source of the explosive. Hence, it is necessary to find out a method that can determine the ions and then to deduce the type of inorganic explosive.

In the present study, simultaneous determination of inorganic explosive residue ions by anion-exchange column and cationexchange column connected directly in series without any switch valves was established. This method was successfully applied to determine the real samples, which was very important for evaluating the type of inorganic explosive. This method was simple, sensitive and cost-effective, and it could be applied in other areas.

\section{Experimental}

\subsection{Apparatus}

The separation of the inorganic explosive residues was performed on the Shimadzu (Kyoto, Japan) PIA-1000 with the following devices: column oven, one pump, manual $10 \mu \mathrm{L}$ injector and non-suppressed conductivity detector. The PIA-1000 is suitable for real-time determination of real sample in explosion site or installation at location with limited space due to its low weight $(15 \mathrm{~kg})$, small cubage $(26 \mathrm{~cm} \times 42 \mathrm{~cm} \times 30 \mathrm{~cm})$ and supplied powder by dc battery or automobile battery. The chromatography data were saved directly onto a floppy disk and then processed using Shimadzu Class-VP software (Version 6.13 SP1). Anion-exchange/cation-exchange simultaneous chromatography separation of anions and cations was carried out using Shim-pack IC-A3 column (i.d. $150 \mathrm{~mm} \times 4.6 \mathrm{~mm}, 5 \mu \mathrm{m}$ particle size, functional group was quaternary ammonium group that has hydrophobic characteristics) and shim-pack IC-C3 column (i.d. $100 \mathrm{~mm} \times 2.0 \mathrm{~mm}, 7 \mu \mathrm{m}$ particle size, functional group was hydroxyl group that has hydrophilic characteristics) directly connected in series as shown in Fig. 1. The experimental conditions for ion chromatography were as follows: column tem-

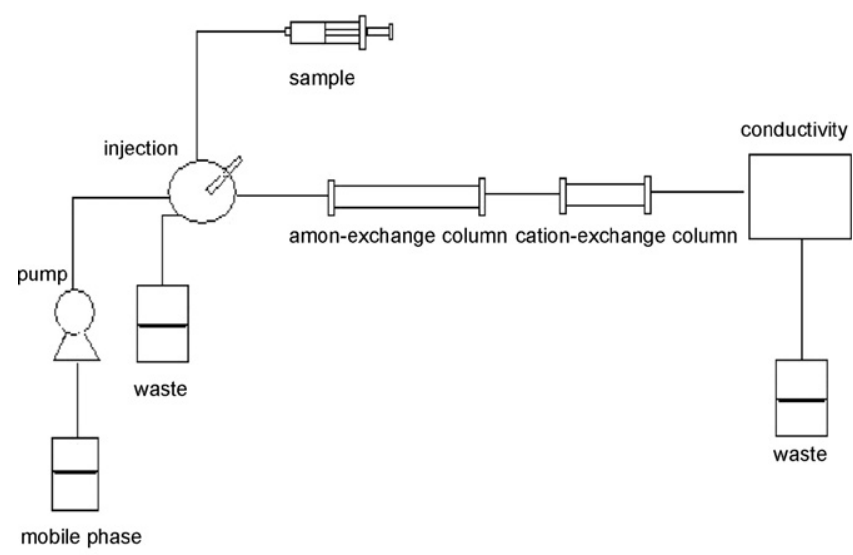

Fig. 1. Experiment apparatus. Anion-exchange/cation-exchange columns directly connected in series.

perature: $35^{\circ} \mathrm{C}$, eluent flow rate: $0.2 \mathrm{~mL} / \mathrm{min}$, injection volume: $10 \mu \mathrm{l}$, detector polarity: +.

\subsection{Reagents}

All chemicals used for the preparation of standard solutions of desired anions, cations and eluent (phthalic acid) were of analytical grade or higher. Methanol and acetonitrile used are of HPLC grade. The stock solution was prepared by dissolving these agents in methanol. And then, this solution was diluted to the desired concentration. All standard solutions were stored in $100 \mathrm{~mL}$ volumetric flask and kept under refrigeration at $4{ }^{\circ} \mathrm{C}$. Deionized water $(>18 \mathrm{M} \Omega$ ) was used for the preparation of standard solutions and eluent. The mobile phase consisted of $3.5 \mathrm{mM}$ phthalic acid with $2 \%$ acetonitrile as the additive, $\mathrm{pH}$ adjusted by Tris, and it was degassed in ultrasonic bath for $20 \mathrm{~min}$ before use. The real sample analyzed was provided by Ministry of Public Security of the People's Republic of China, and was filtered by $0.45 \mu \mathrm{m}$ filters before analysis.

\section{Result and discussion}

\subsection{Eluent conditions}

In non-suppressed ion chromatography, weak acids were usually employed as the eluent for simultaneous separation of anions and cations for their low background conductivity. Some weak acids, such as phthalic acid [7], sulfosalicylic acid [16,19], tartaric acid [17], were commonly used in non-suppressed system as the eluent for simultaneous determination of anions and cations.

In the present study, the group of anion-exchange column functional was hydrophobic, and that of cation-exchange column functional was hydrophilic. If the eluent had no hydrophobic group, the anion-exchange column cannot adsorb the eluent for ion exchange with inorganic anions, and the same reason is for cation-exchange column. Therefore, the eluent of both hydrophobic group and hydrophilic group should be chosen. Phthalic acid has been chosen as the eluent to determine anions 


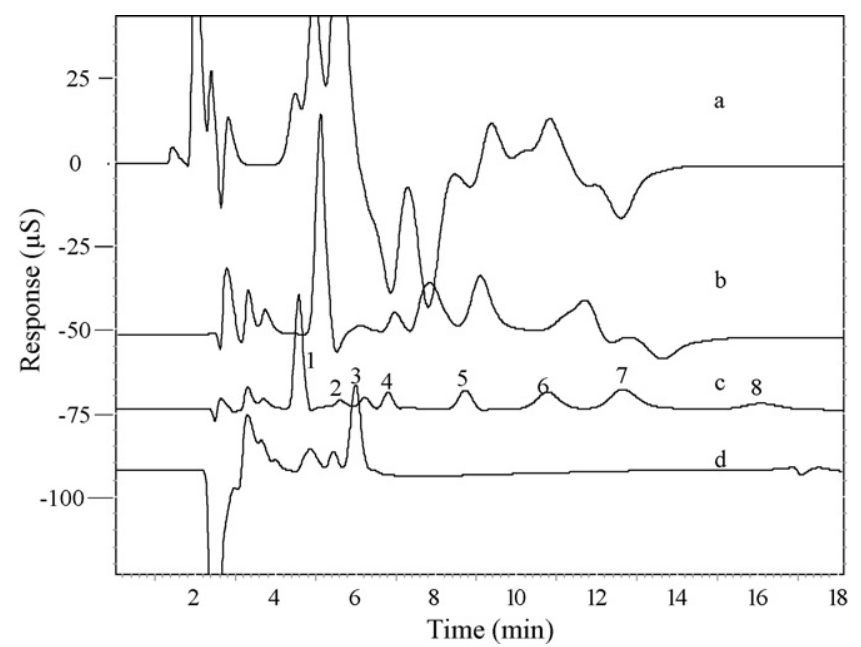

Fig. 2. Effect of eluent $\mathrm{pH}$. Column: shim-pack ICA3 $(150 \mathrm{~mm} \times 4.6 \mathrm{~mm}$ i.d. $)$ and shim-pack IC-C3 $\left(100 \mathrm{~mm} \times 2 \mathrm{~mm}\right.$ i.d.). Column temperature: $35^{\circ} \mathrm{C}$. Inject volume: $10 \mu$ l. Eluent flow rate: $0.2 \mathrm{~mL} / \mathrm{min}$. (a) $\mathrm{pH} 3.0$, (b) $\mathrm{pH} 3.5$, (c) $\mathrm{pH} 4.0$ and (d) $\mathrm{pH}$ 4.5. Peak identities: (1) $\mathrm{Cl}^{-}$, (2) $\mathrm{NO}_{2}{ }^{-}$, (3) $\mathrm{ClO}_{3}{ }^{-}$, (4) $\mathrm{NO}_{3}{ }^{-}$, (5) $\mathrm{SO}_{4}{ }^{2-},(6) \mathrm{Na}^{+}$, (7) $\mathrm{NH}_{4}{ }^{+}$and (8) $\mathrm{K}^{+}$.

and cations simultaneously, considering that phthalic acid contains strong hydrophobic benzene ring and hydrophilic hydroxyl group.

\subsection{Effect of $p H$ of eluent}

The $\mathrm{pH}$ of eluent was the most important factor to separate and determine inorganic anions and cations, especially polycarboxylic acids as the eluent. The exchangeable ions of eluent depend on $\mathrm{pH}$, since the eluents for non-suppressed ion chromatography were hydroxy acid that mostly possess several $\mathrm{p} K_{\mathrm{a}}$ values. Under different $\mathrm{pH}$, hydroxy acid ions appear to be different ionic species, which offer different ion-exchange abilities. Therefore, the adjusting $\mathrm{pH}$ could control the quantity of the exchangeable ions of the eluent. The $\mathrm{pH}$ affects both the retention time and resolution of ions, especially for divalent ions. Phthalic acid was a binary weak acid, which has two $\mathrm{p} K_{\mathrm{a}}$ 's $\left(\mathrm{p} K_{\mathrm{a}_{1}}=2.95, \mathrm{p} K_{\mathrm{a}_{2}}=5.41\right)$. In the present study, the $\mathrm{pH}$ range of $3-5$ was investigated according to the $\mathrm{pH}$ tolerance range of the columns ( $\mathrm{pH} \mathrm{3-7}$ for the anion-exchange column, and $\mathrm{pH} 2-5$ for cation-exchange column). As shown in Fig. 2, when $\mathrm{pH}$ of the eluent was 3.0, two big system peaks appeared, peaks hard to identify and possess poor resolution. With the increase in the $\mathrm{pH}$, peak shapes and resolutions improved. However, when $\mathrm{pH}$ was higher than 4.5, ions peaks overlapped and the resolution and peak shape become poorer than those under $\mathrm{pH}$ 4.0. Therefore, $\mathrm{pH} 4.0$ was selected in the following experiments.

\subsection{Effect of phthalic acid concentration}

The effect of phthalic acid concentration in eluent on the retention time of anions and cations was investigated as well. As shown in Fig. 3, $\mathrm{SO}_{4}{ }^{2-}$ could be eluted by the eluent, until the phthalic acid concentration was higher than $2.5 \mathrm{mM}$. With the concentration of phthalic acid increasing, the retention time

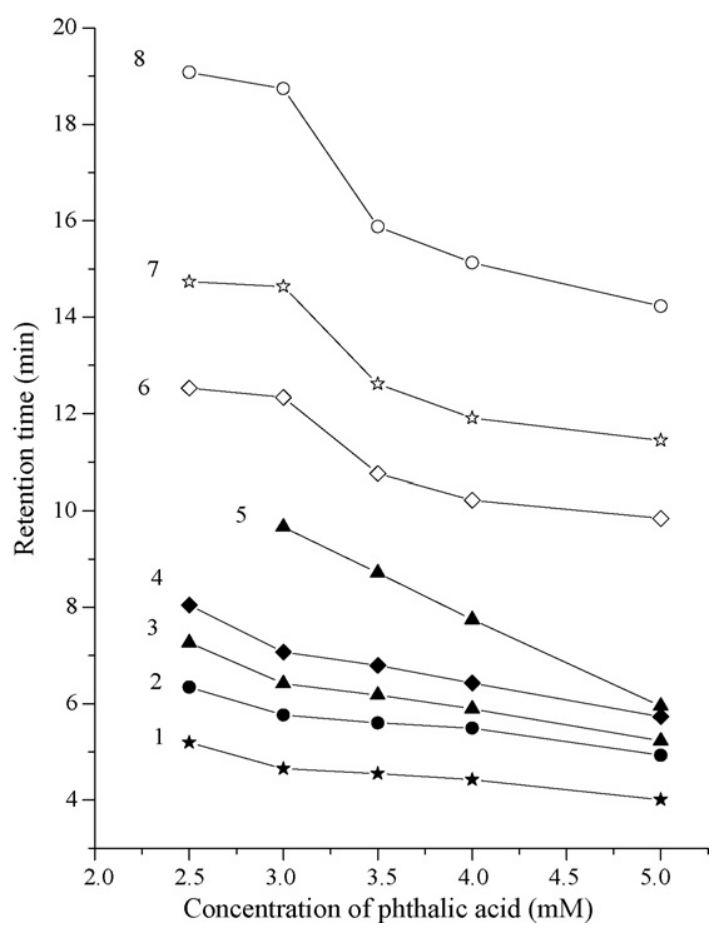

Fig. 3. Effect of phthalic acid concentration on retention time of inorganic ions.

of ions decreased, especially for the divalent ions $\mathrm{SO}_{4}{ }^{2-}$, which was more influenced by the ion-exchange effect. At the same time, the resolution of inorganic ions also decreased as the phthalic acid concentration increased. In conclusion, the retention time and resolution of anions and cations both decreased with the increase of the phthalic acid concentration. The peak of inorganic cations was wider than that of anions because the phthalic acid of ion-exchange ability for cations was not strong as anions.

The background conductance increased with concentration of phthalic acid in the eluent $(231 \mu \mathrm{S} / \mathrm{cm}$ for a $2.5 \mathrm{mM}$ eluent, $261 \mu \mathrm{S} / \mathrm{cm}$ for a $3 \mathrm{mM}$ eluent, $296 \mu \mathrm{S} / \mathrm{cm}$ for a $3.5 \mathrm{mM}$, $329 \mu \mathrm{S} / \mathrm{cm}$ for a $4 \mathrm{mM}$ eluent, and $399 \mu \mathrm{S} / \mathrm{cm}$ for a $5 \mathrm{mM}$ eluent). The increase of the phthalic acid concentration of the phthalic acid caused decrease in the sensitivity of conductivity detection. Therefore, the low phthalic acid concentration should be chosen. Taking the retention time, the resolution and the sensitivity into consideration, the optimal concentration of phthalic acid was $3.5 \mathrm{mM}$. The corresponding chromatography was shown in Fig. 4.

\subsection{Effect of additive in the mobile phase}

Some organic solvents, such as acetonitrile, methanol, can effectively improve resolution, peaks shape and retention time. Addition of eluent has been known to be very effective to improve resolutions and peaks shape. The influence of acetonitrile on the retention time of anions and cations was also investigated in the present work. Acetonitrile can occupy the hydrophobic position of ion-exchange resin, and reduce the nonion-exchange reaction of target inorganic ions and ion-exchange resin, at the same time; acetonitrile possesses hydrophobic char- 


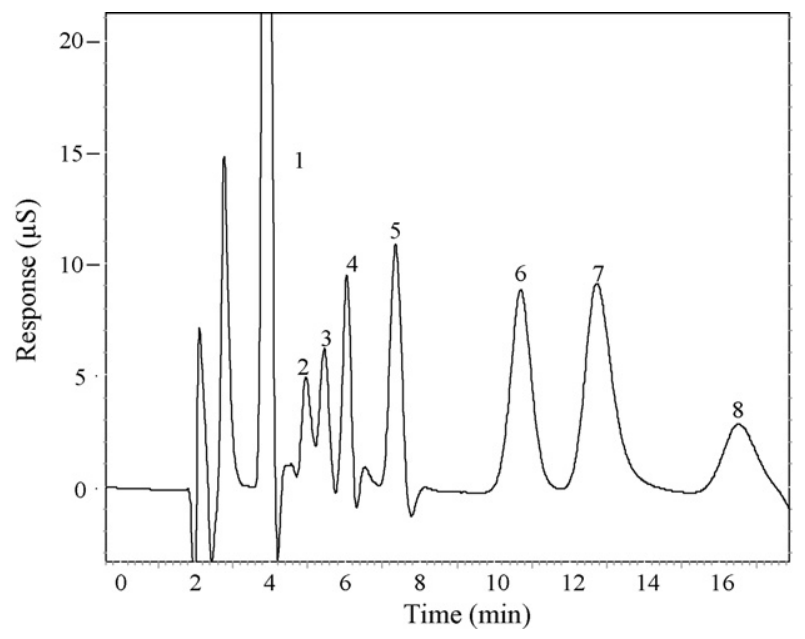

Fig. 4. Anion-exchange/cation-exchange chromatography of inorganic ions by eluent with $3.5 \mathrm{mM}$ phthalic acid. $\mathrm{pH}: 4.0$; (1) $\mathrm{Cl}^{-}$, (2) $\mathrm{NO}_{2}{ }^{-}$, (3) $\mathrm{ClO}_{3}{ }^{-}$, (4) $\mathrm{NO}_{3}{ }^{-}$, (5) $\mathrm{SO}_{4}{ }^{2-}$, (6) $\mathrm{Na}^{+}$, (7) $\mathrm{NH}_{4}^{+}$and (8) $\mathrm{K}^{+}$. Other conditions are as in Fig. 2.

acter, and increases the hydrophobicity of eluent [24]. The resolution, peaks shape and retention time were affected by the two factors simultaneously. As shown in Fig. 5, the retention time of cations became more shorter, and the retention time of anions became more longer. Resolution and peaks shape of anions and cations all became more and more better along with the increasing acetonitrile volume. Acetonitrile has no significant effect on retention time of monovalent anions and cations, but the divalent anion $\mathrm{SO}_{4}{ }^{2-}$ increased significantly. When acetonitrile was added to $8 \%(\mathrm{v} / \mathrm{v}), \mathrm{SO}_{4}{ }^{2-}$ and $\mathrm{Na}^{+}$were not

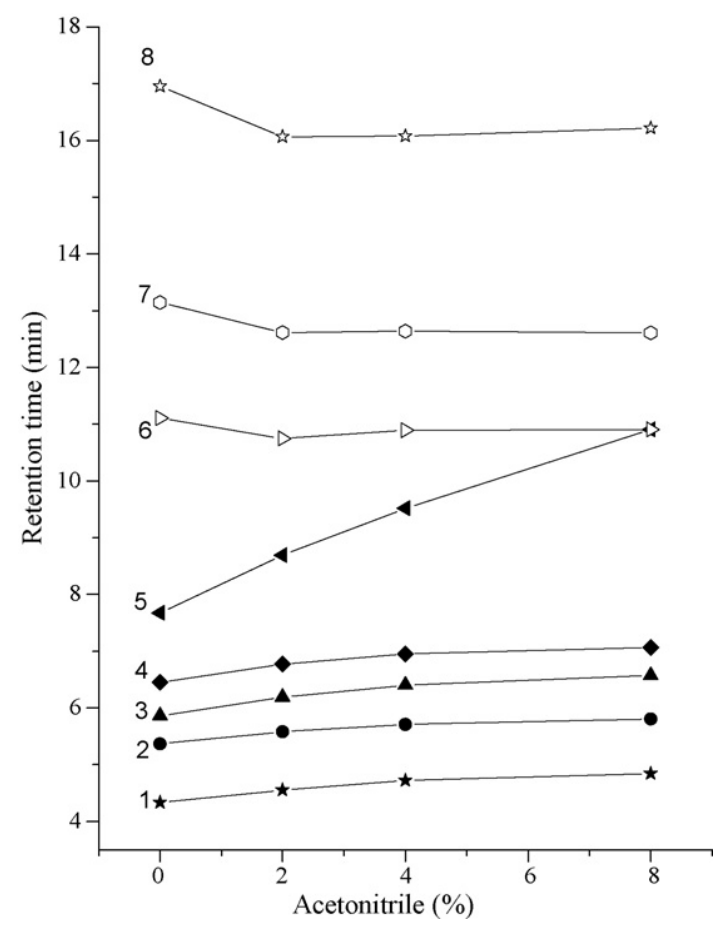

Fig. 5. Effect of volume percentage acetonitrile in $3.5 \mathrm{mM}$ phthalic acid eluent on retention time of inorganic ions. (1) $\mathrm{Cl}^{-}$, (2) $\mathrm{NO}_{2}^{-}$, (3) $\mathrm{ClO}_{3}{ }^{-}$, (4) $\mathrm{NO}_{3}^{-}$, (5) $\mathrm{SO}_{4}{ }^{2-}$, (6) $\mathrm{Na}^{+}$, (7) $\mathrm{NH}_{4}{ }^{+}$and (8) $\mathrm{K}^{+}$. Other conditions are as in Fig. 2.

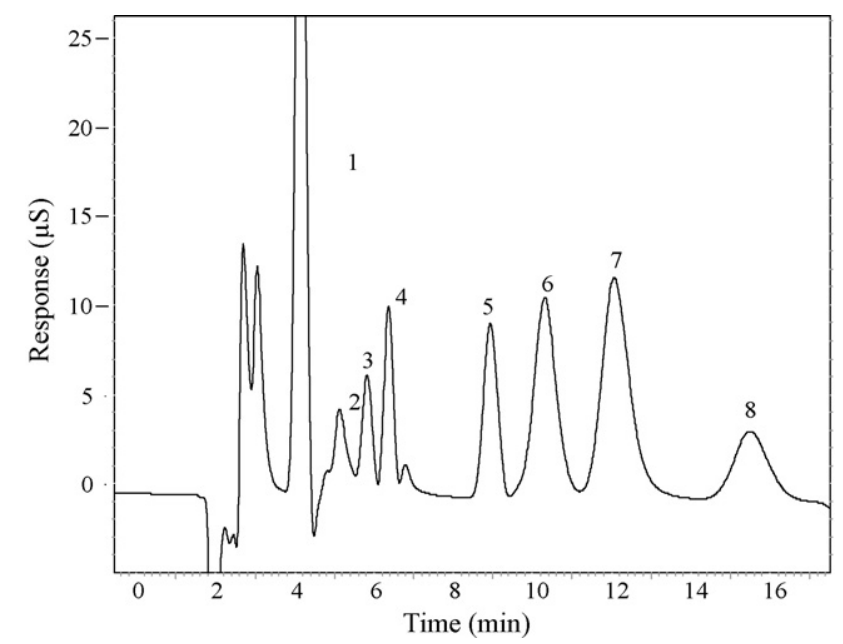

Fig. 6. Anion-exchange/cation-exchange chromatography of inorganic ions by eluent with $3.5 \mathrm{mM}$ phthalic acid, $2 \%$ acetonitrile, anion-exchange/cationexchange connect order. Eluent pH: 4.0; (1) $\mathrm{Cl}^{-}$, (2) $\mathrm{NO}_{2}^{-}$, (3) $\mathrm{ClO}_{3}^{-}$, (4) $\mathrm{NO}_{3}^{-}$, (5) $\mathrm{SO}_{4}{ }^{2-}$, (6) $\mathrm{Na}^{+}$, (7) $\mathrm{NH}_{4}^{+}$and (8) $\mathrm{K}^{+}$. Eluent conductivity: $293 \mu \mathrm{S} / \mathrm{cm}$. Other conditions are as in Fig. 2.

separated. Hence, $2 \%$ acetonitrile was added in the eluent as the optimal amounts of additive.

\subsection{Effect of the order of ion-exchange columns in series}

The order of the columns connected has slight effect on the peak shapes, but has no effect on retention time. The cationexchange column connects follow anion-exchange column show slightly better performance on peak shape than vice versa. Two types connect have similar retention time. The cations slightly retained in anion-exchange column and passed thorough the anion-exchange column quickly. The anions have the same retention behavior in cation-exchange column. Hence, the order of ion-exchange columns connect was not the major factor influence separate and determine inorganic ions. The cationexchange column follow anion-exchange column was chosen in this study.

As shown in Fig. 6, simultaneous determination of inorganic anions and cations by connecting anion-exchange/cationexchange columns was obtained within 16 min using an eluent composed of $3.5 \mathrm{mM}$ phthalic acid, $2 \%$ acetonitrile, $\mathrm{pH} 4.0$.

\subsection{Analytical performance characteristics}

The calibration graphs of these anions and cations were obtained by plotting peak areas versus concentration at the optimal conditions of anion-exchange/cation-exchange chromatography system. The concentration of anions and cations were in the range of $0.1-20 \mathrm{mg} / \mathrm{L}$ for anions and cations $\left(\mathrm{NO}_{2}{ }^{-}, \mathrm{ClO}_{3}{ }^{-}, \mathrm{NO}_{3}{ }^{-}, \mathrm{SO}_{4}{ }^{2-}, \mathrm{NH}_{4}{ }^{+}, \mathrm{K}^{+}\right)$, and $0.28-57.6 \mathrm{mg} / \mathrm{L}$ for $\mathrm{Cl}^{-}, 0.16-32.60 \mathrm{mg} / \mathrm{L}$ for $\mathrm{Na}^{+}$, as shown in Table 1 . The limits of detection (LODs, $\mathrm{S} / \mathrm{N}=3$ ) and recovery were also given in Table 1 . The reproducibility was evaluated by six consecutive runs at the concentration of $5 \mathrm{mg} / \mathrm{L}$. The R.S.D. of retention time and peak area were $0.10-0.29 \%$ and $5.65-8.12 \%$, respectively. The poorer reproducibility for peak 
Table 1

LODs, correlation coefficient $\left(r^{2}\right)$ and the retention time $\left(t_{\mathrm{R}}\right)$ of anions and cations obtained from the optimum chromatography condition as in Fig. 6

\begin{tabular}{lllcc}
\hline Analyte & LODs $(\mu \mathrm{g} / \mathrm{L})$ & $r^{2}$ & $t_{\mathrm{R}}(\min )$ & Recovery $(\%)$ \\
\hline $\mathrm{Cl}^{-}$ & 115 & 0.9972 & 4.63 & 108 \\
$\mathrm{NO}_{2}{ }^{-}$ & 300 & 0.9984 & 5.66 & 104 \\
$\mathrm{ClO}_{3}{ }^{-}$ & 300 & 0.9989 & 6.30 & 94.8 \\
$\mathrm{NO}_{3}{ }^{-}$ & 50 & 0.9984 & 6.87 & 104 \\
$\mathrm{SO}_{4}{ }^{2-}$ & 70 & 0.9996 & 8.82 & 109 \\
$\mathrm{Na}^{+}$ & 320 & 0.9989 & 10.65 & 91 \\
$\mathrm{NH}_{4}{ }^{+}$ & 150 & 0.9994 & 12.47 & 82 \\
$\mathrm{~K}^{+}$ & 300 & 0.9941 & 15.82 & 109 \\
\hline
\end{tabular}

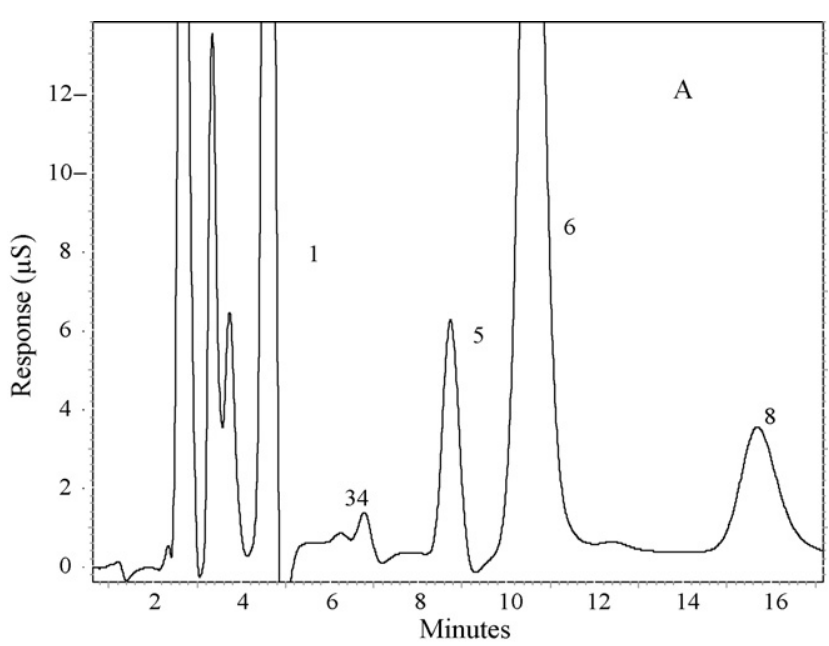

Fig. 7. Anion-exchange/cation-exchange chromatography of anions and cations in the inorganic explosive residues from Ministry of Public Security of the People's Republic of China. Other conditions are as in Fig. 2.

areas was because of the manual injection and inaccurate integration.

\subsection{Application to inorganic explosive residues}

The validated method was successfully applied to the simultaneous separation and determination of inorganic explosive

Table 2

Determination of major anions and cations concentration in inorganic explosive residues $(n=3)$

\begin{tabular}{llll}
\hline Analyte & \multicolumn{2}{l}{ Inorganic explosive residues $(\mathrm{mg} / \mathrm{L})$} \\
\cline { 2 - 4 } & Sample 1 & Sample 2 & Sample 3 \\
\hline $\mathrm{Cl}^{-}$ & $19.926( \pm 0.52 \%)$ & $1.787( \pm 0.36)$ & $26.427( \pm 0.42)$ \\
$\mathrm{NO}_{2}{ }^{-}$ & n.d. & n.d. & n.d. \\
$\mathrm{ClO}_{3}{ }^{-}$ & $0.462( \pm 0.32 \%)$ & n.d. & n.d. \\
$\mathrm{NO}_{3}{ }^{-}$ & $0.764( \pm 0.07 \%)$ & $4.142( \pm 0.09)$ & $71.269( \pm 0.05)$ \\
$\mathrm{SO}_{4}{ }^{2-}$ & $6.051( \pm 0.56 \%)$ & $14.096( \pm 0.5)$ & $42.303( \pm 0.61)$ \\
$\mathrm{Na}^{+}$ & $38.589( \pm 0.62 \%)$ & $3.382( \pm 0.71)$ & $22.259( \pm 0.59)$ \\
$\mathrm{NH}_{4}{ }^{+}$ & n.d. & $1.312( \pm 0.37)$ & n.d. \\
$\mathrm{K}^{+}$ & $7.837( \pm 0.26 \%)$ & $1.731( \pm 0.38)$ & $10.470( \pm 0.37)$ \\
\hline
\end{tabular}

\footnotetext{
${ }^{a}$ Not detected.
}

residues. It is important for forensic analysis to evaluate the types of explosives. Fig. 7 illustrates the chromatogram of explosive residues taken from several explosion sites by Ministry of Public Security of the People's Republic of China, major anions and cations $\left(\mathrm{Cl}^{-}, \mathrm{NO}_{3}{ }^{-}, \mathrm{SO}_{4}{ }^{2-}, \mathrm{Na}^{+}\right.$and $\left.\mathrm{K}^{+}\right)$were determined in these samples. The nature of $\mathrm{NO}_{2}{ }^{-}$is instable, so the content of $\mathrm{NO}_{2}{ }^{-}$in the soil is too slightly to be detected. The data for three samples are summarized in Table 2.

\section{Conclusion}

Anion-exchange column and cation-exchange column were connected directly for the simultaneous separation and determination of anions and cations which was usually found in inorganic explosive. The optimized eluent containing $3.5 \mathrm{mM}$ phthalic acid, $2 \%$ acetonitrile, $\mathrm{pH} 4.0$, showed good performance for the simultaneous determination of anions and cations of the inorganic explosive residues within $16 \mathrm{~min}$. The methods developed could meet the need of the simultaneous determination of the field conditions, as a portable IC instrument was used in the present investigation.

\section{References}

[1] Z.L. Chen, M. Megharaj, R. Naidu, Talanta 72 (2007) 1842.

[2] Y.J. Liu, S.F. Mou, Microchem. J. 75 (2003) 79.

[3] R. Li, W.L. Lee, T. Takeuchi, Talanta 72 (2007) 1625.

[4] P. Miskaki, E. Lytrad, L. Kousouris, P. Tzoumerkas, Desalination 213 (2007) 182.

[5] K. Zhang, Y.S. Wang, T.X. Wen, Y. Meslmani, F. Murray, Atmos. Res. 84 (2007) 67.

[6] K.J. Yoshkawa, M. Okamura, M. Inokuchi, S. Akio, Talanta 72 (2007) 305.

[7] S.N. Walford, J. Chromatogr. A 956 (2002) 187.

[8] Z. Yan, Y.Y. Guo, M.L. Ye, F.S. James, J. Chromatogr. A 1085 (2005) 143.

[9] Z.F. Chen, B.W. Darvell, V.W.-H. Leung, Arch. Oral Biol. 49 (2004) 863.

[10] L. Valentin-Blasini, B.C. Blount, A. Delinsky, J. Chromatogr. A 1155 (2007) 40-46.

[11] B.S. Yu, Q.G. Yuan, L.H. Nie, S.Z. Yao, J. Pharm. Biomed. 25 (2001) $1027-1032$.

[12] H.E. Aribi, Y.J.C.L. Blanc, S. Antonsen, T. Sakuma, Anal. Chim. Acta 567 (2006) 39.

[13] J.M. Doyle, B.R. McCord, J. Chromatogr. B 714 (1998) 105.

[14] T. Kishi, J. Nakamura, H. Arai, Electrophoresis 19 (1998) 3.

[15] S.R. Aari-Nordhaus, J.M. Anderson Jr., J. Chromatogr. 549 (1991) 257.

[16] R. Saari-Nordhaus, L. Nair, J.M. Anderson Jr., J. Chromatogr. 602 (1992) 127.

[17] A. Muhammad, W.L. Lee, T. Toyohide, Talanta 71 (2007) 1470.

[18] K.J.B.A. Karim, J.Y. Jin, T. Takeuchi, J. Chromatogr. A 995 (2003) 153.

[19] K. Tanaka, K. Ohta, P.R. Haddad, J.S. Fritaz, A. Miyanaga, W.Z. Hu, K. Hasebe, J. Chromatogr. A 884 (2000) 167.

[20] M. Mori, K. Tanaka, M.I.H. Helaleh, Q. Xu, M. Ikedo, Y. Ogura, S. Sato, W.Z. Hu, K. Hasebe, P.R. Haddad, J. Chromatogr. A 997 (2003) 219.

[21] M. Mori, K. Tanaka, T.I.M. Satori, W.Z. Hu, H. Itabashi, J. Chromatogr. A 1118 (2006) 51.

[22] J.P. Hutchinson, C.J. Evenhuis, C. Johns, A.A. Kazarian, M.C. Breadmore, M. Macka, E.F. Hilder, R.M. Guijt, G.W. Dicinoski, P.R. Haddad, Anal. Chem. 79 (2007) 7005.

[23] E.T. Urbansky, Crit. Rev. Anal. Chem. 30 (2000) 311.

[24] X.J. Ding, S.F. Mou, J. Chromatogr. A 897 (2000) 205. 